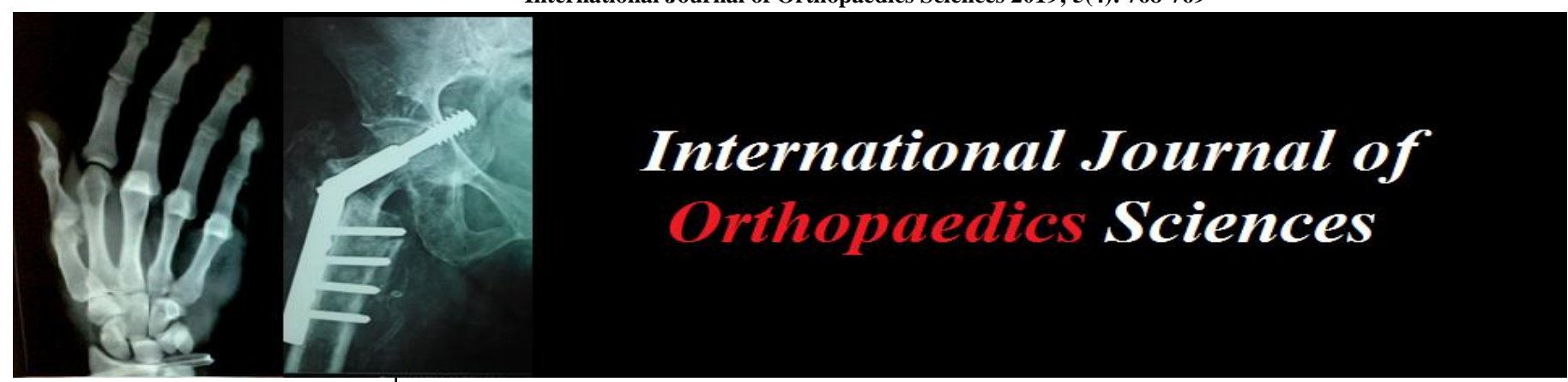

E-ISSN: 2395-1958

P-ISSN: 2706-6630

IJOS 2019; 5(4): 768-769

(C) 2019 IJOS

www.orthopaper.com

Received: 25-08-2019

Accepted: 27-09-2019

Dr. Nagaraj BN

Associate Professor,

Department of Orthopaedics,

Akash Institute of Medical

Science and Research Centre,

Bengaluru, Karnataka, India

Corresponding Author:

Dr. Nagaraj BN

Associate Professor,

Department of Orthopaedics,

Akash Institute of Medical

Science and Research Centre,

Bengaluru, Karnataka, India

\section{Management of thoracolumbar fractures: A prospective study}

\section{Dr. Nagaraj BN}

DOI: https://doi.org/10.22271/ortho.2019.v5.i4m.1769

\section{Abstract}

Thoracolumbar fractures are breakages in the vertebrae of the spinal column in the thoracic and lumbar regions. They may be associated with disruption of the ligamentous complexes, and can result in instability or compression of neural structures. Thoracolumbar fractures are the usual outcome of thoracolumbar trauma. In the present study, Thoracolumbar spine fractures are more common in 31-40 years of life with male predominance due to outdoor activities, the commonest mode of injury was road traffic accident, In the present study, Type A fracture is more common at the level of L1. In this series 12 patients polyaxial pedicle screws were used and in 4 patients monoaxial with polyaxial pedicle screws were used. Fracture-dislocations of the thoracic and lumbar spine are caused by very high-energy trauma. They can be extremely unstable injuries that often result in serious spinal cord or nerve damage.

Keywords: Thoracolumbar fractures, type a fracture, monoaxial with polyaxial pedicle screws

\section{Introduction}

Thoracolumbar fractures are breakages in the vertebrae of the spinal column in the thoracic and lumbar regions. They may be associated with disruption of the ligamentous complexes, and can result in instability or compression of neural structures. Thoracolumbar fractures are the usual outcome of thoracolumbar trauma. Other outcomes include traumatic disk prolapse, ligamentous injury, and epidural hematoma causing pressure on the spinal cord or nerve roots; these occur very rarely without a fracture. This monograph focuses on thoracolumbar spine fracture.

Usually occurs as a result of high-energy trauma (e.g., road traffic accidents, falls from heights). May occur spontaneously in patients with osteoporotic, neoplastic, or metabolic disorders of the spine. Initial on-the-scene evaluation involves performing primary survey with $\mathrm{ABC}$ assessment with $\mathrm{C}$-spine immobilization and hemorrhage control. It is important to evaluate and assess thoracolumbar fractures for instability. If the decision to operate is made, this should occur earlier rather than later.

There are different types of spinal fractures. Doctors classify fractures of the thoracic and lumbar spine based upon the specific pattern of the fracture and whether there is a spinal cord injury. Classifying the fracture pattern will help your doctor determine the proper treatment. ${ }^{1}$

The three major types of spine fracture patterns are:

- Flexion

- Extension

- Rotation

\section{Flexion fracture pattern}

Compression fracture: While the front (anterior) of the vertebra breaks and loses height, the back (posterior) part of it does not. This type of fracture is usually stable (the bones have not moved out of place) and is rarely associated with neurologic problems. Compression fractures commonly occur in patients with osteoporosis.

\section{Extension fracture pattern}

Flexion/distraction (Chance) fracture: The vertebra is literally pulled apart (distraction). This type of fracture can occur in a head-on car collision when the upper body is thrown forward while the pelvis is stabilized by a lap seat belt. 


\section{Rotation fracture pattern}

Transverse process fracture: This uncommon fracture results from rotation or extreme sideways (lateral) bending. It does not usually affect stability.

Objective: To determine the commonest modes, level, and type of fracture and to study radiological, radiological, and clinical outcome.

\section{Methodology}

A total of 20 cases were evaluated and assessed during the study period.

\section{Inclusion criteria}

1. Age group $>18 y$ rs

2. Traumatic thoracolumbar fractures.

3. Unstable fractures with or without neurological deficits.

\section{Exclusion criteria}

1. Age $<18$ yrs.

2. Traumatic cervical spine fractures and sacral spinal fracture.

3. Spinal instability due to congenital spinal abnormality.

4. Patients not willing for surgery.

5. Medically unfit for surgery.

\section{Results}

Table 1: Age and Sex wise distribution of cases

\begin{tabular}{|c|c|c|c|}
\hline Age group & Male & Female & Total \\
\hline 10- 20 years & 00 & 00 & 00 \\
\hline 21- 30 years & 03 & 00 & 03 \\
\hline 31-40 years & 06 & 01 & 07 \\
\hline 41- 50 years & 05 & 01 & 06 \\
\hline 51-60 years & 03 & 01 & 04 \\
\hline Total & 17 & 03 & 20 \\
\hline
\end{tabular}

Table 2: Manner wise distribution of cases

\begin{tabular}{|c|c|}
\hline Manner & Number \\
\hline Road traffic accident & 12 \\
\hline Fall from height & 08 \\
\hline
\end{tabular}

Table 3: Distribution of cases based on Type

\begin{tabular}{|c|c|}
\hline Type of fracture & Number \\
\hline AO Type A & 12 \\
\hline AO Type B & 04 \\
\hline AO Type C & 04 \\
\hline
\end{tabular}

Table 4: Distribution of cases based on level of fracture

\begin{tabular}{|c|c|}
\hline Level of fracture & Number \\
\hline T 11 & 0 \\
\hline T 12 & 6 \\
\hline L 1 & 9 \\
\hline L 2 & 5 \\
\hline
\end{tabular}

Table 5: Distribution of cases based on type of Implant

\begin{tabular}{|c|c|}
\hline Implant & Number \\
\hline Polyaxial & 12 \\
\hline Monoaxial + polyaxial & 08 \\
\hline
\end{tabular}

\section{Discussion}

In the present study, Thoracolumbar spine fractures are more common in 31-40 years of life with male predominance due to outdoor activities. Gregory F. Alvine et al in their study found that average age was 31 years, with a male predominance.
Nasser M.G, et al in their study found that average age was 28.8 years with a male predominance. Rick C. Sasso et al, in their study had $77 \%$ males and $23 \%$ females with a mean age of 34 years. Razak M, et al in their study found that average was 30 years with a male predominance ${ }^{[2,3]}$.

In the present study, the commonest mode of injury was road traffic accident. Nasser M.G, et al in his study noted that the main cause of injury was fall from a height and road traffic accident was the second commonest. Gregory F. Alvine, et al noted that in $52 \%$ of patients injuries resulted form fall from a height, in 39\% patients due to road traffic accidents and $9 \%$ due to fall of heavy objective. Razak M, et al in his study noted that $69 \%$ of injuries were caused from fall from height, $31 \%$ due to road traffic accident ${ }^{[3,4]}$.

In the present study, Type A fracture is more common at the level of L1. In this series 12 patients polyaxial pedicle screws were used and in 4 patients monoaxial with polyaxial pedicle screws were used. Nasser M.G. et al., in their study noted $76 \%$ of patients with Type-A, $8 \%$ with Type-B and $16 \%$ with Type-C. Rick C.Sasso et al., noted that $62.5 \%$ had AO Type$\mathrm{B}$ and $37.5 \%$ had AO Type-A fractures. Gregory F.Alvine et al noted that Type-B fractures were seen in $57.5 \%$ of patients Type-A in $22.5 \%$ and $20 \%$ Type- $C^{[5,6]}$.

\section{Conclusion}

Fracture-dislocations of the thoracic and lumbar spine are caused by very high-energy trauma. They can be extremely unstable injuries that often result in serious spinal cord or nerve damage. These injuries require stabilization through surgery. The ideal timing of surgery can often be complicated. Surgery is sometimes delayed because of other serious, lifethreatening injuries.

\section{References}

1. Jens R. Chapman Sohail K, Mirza H. Rockwood and Green Fractures in Adults. Lippincott Williams and Wilkins, 5th edition. 2: 1295-1466.

2. Blick EM. Source of orthopaedics Baltimore. Williams and Wilkins. 1948; 236-238.

3. Riggins RS. Kraus JF. The risk of neurological damage with fractures of the vertebrae. Journal of Trauma, 1977, 126-133.

4. Benson DR. Keenen TL. Evaluation and Treatment of Trauma to the Vertebral Column. Journal of Bone and Joint Surgery 1990; 39:577-588.

5. Marvin R Leventhal. Fracture, dislocations, and fracture dislocation of spine, chapter 35, vol 2 10th edition. Edt Canale S. Terry Missouri, Mosby. 2003; 1597-1690.

6. Gunmann L. The treatment and rehabilitation of patients with injuries of spinal cord. In Cope 2; Edn: Medical history of the second world war: Surgery, London 1953, His Majesty Stationary office. 